\title{
Induced Pluripotent Stem Cells Provide an Unlimited T-cell Source for CAR-T cell Development and A Potential Source for Off-the-shelf Products
}

\author{
Muhammad Sadeqi Nezhad ${ }^{1}$ \\ ${ }^{1}$ Islamic Azad University
}

April 7, 2021

\begin{abstract}
CAR-T cell therapy has been increasingly conducted for cancer patients in clinical settings. Progress in this therapeutic approach is hampered by the lack of a solid manufacturing process, T lymphocytes, and tumor-specific antigens. T-cell source used in CAR-T cell therapy is predominantly derived from the patient's own T lymphocytes, which makes this approach impracticable to patients with progressive diseases and T leukemia. Autologous CAR-T cell generation is time-consuming due to lack of readily available $\mathrm{T}$ lymphocytes and is not applicable for third-party patients. Pluripotent stem cells, such as human induced pluripotent stem cells (hiPSCs), could provide an unlimited T-cell source for CAR-T cell development. iPSC-derived $\mathrm{T}$ cells would be a promising infinite T-cell source and are phenotypically defined, expandable and functional as physiological $\mathrm{T}$ cells. iPSC-derived $\mathrm{T}$ cells provide a feasible T-cell source for the development of off-the-shelf $\mathrm{T}$ cells and CAR-T cells. The combination of iPSC and CAR-Technologies provides an extraordinary opportunity to oncology and greatly facilitates cell-based therapy for cancer patients. T-iPSCs in combination with CAR is in early stage of development and the pre-clinical and clinical studies concerning the combination of these novel technologies are not sufficient. This article critically reviews the progress in iPSC-derived $\mathrm{T}$ cell development and provides a roadmap for development of CAR iPSC-derived T cells and off-the-shelf T-iPSCs.
\end{abstract}

Keywords: CAR-T cell; iPSC; T cell; iPSC-derived T cell; tumor cell; therapeutic; off-the-shelf

Induced Pluripotent Stem Cells Provide an Unlimited T-cell Source for CAR-T cell Development and A Potential Source for Off-the-shelf Products

Muhammad Sadeqi Nezhad 1,2, Meghdad Abdollahpour-Alitappeh 3, Behzad Rezaei 4 ,

Alexander Seifalian $5^{*}$

1 Department of Clinical Laboratory Science, Azad University, 2 Blood Transfusion Research Center,

High Institute for Research and Education in Transfusion Medicine, Gorgan, Iran, 3 Cellular and

Molecular Biology Research Center, 4 Department of Surgery, Larestan University of Medical

Sciences, Larestan, Iran, 5 Nanotechnology \&amp; Regenerative Medicine Commercialization Centre (Ltd),

London BioScience Innovation Centre, London, United Kingdom

Alexander Marcus Seifalian (ORCID: 0000-0002-8334-9376)

Director/Professor of Nanotechnology \&amp; Regenerative Medicine

E-Mail: a.seifalian@gmail.com, Tel: +442076911122 , Mobile: +4479853806797

\section{Abstract}


CAR-T cell therapy has been increasingly conducted for cancer patients in clinical settings. Progress in this therapeutic approach is hampered by the lack of a solid manufacturing process, $\mathrm{T}$ lymphocytes, and tumor-specific antigens. T-cell source used in CAR-T cell therapy is predominantly derived from the patient's own T lymphocytes, which makes this approach impracticable to patients with progressive diseases and T leukemia. Autologous CAR-T cell generation is time-consuming due to lack of readily available $\mathrm{T}$ lymphocytes and is not applicable for third-party patients. Pluripotent stem cells, such as human induced pluripotent stem cells (hiPSCs), could provide an unlimited T-cell source for CAR-T cell development. iPSCderived $\mathrm{T}$ cells would be a promising infinite T-cell source and are phenotypically defined, expandable and functional as physiological T cells.iPSC-derived T cells provide a feasible T-cell source for the development of off-the-shelf $\mathrm{T}$ cells and CAR-T cells. The combination of iPSC and CAR-Technologies provides an extraordinary opportunity to oncology and greatly facilitates cell-based therapy for cancer patients. T-iPSCs in combination with CAR is in early stage of development and the pre-clinical and clinical studies concerning the combination of these novel technologies are not sufficient. This article critically reviews the progress in iPSC-derived T cell development and provides a roadmap for development of CAR iPSC-derived T cells and off-the-shelf T-iPSCs.

Keywords: CAR-T cell; iPSC; T cell; iPSC-derived T cell; tumor cell; therapeutic; off-the-shelf

1- $\quad$ PBMCs are a promising somatic cell source for iPSC-derived T cell generation

2- $\quad$ iPSC-derived $\mathrm{T}$ cells provide an unlimited $\mathrm{T}$ cell source for CAR-T cell development

3- $\quad$ iPSC-derived T cells can be engineered with artificial receptors, CARs, and showed therapeutic potential

4- The combination of iPSC and CAR technologies is in preliminary stage of investigation and so many questions remained with no constructive answers

Running title: Application of iPSC-derived T cell for CAR-T development

\section{Introduction:}

Adoptive cell therapy (ACT) is a new form of cancer treatment that empowers $\mathrm{T}$ cells through genetic engineering to express either T-cell receptors or chimeric antigen receptors (CARs) to recognize and destroy the malignant cells [1]. ACT manipulates and alters the capacity and anti-tumor response of physiological $\mathrm{T}$ cells for a robust immune response against infected or abnormal cells [2]. ACT using CD19 CAR-T cells has led to outstanding responses in patients with certain types of hematologic malignancies, such as large B-cell lymphoma and B-cell acute lymphoblastic leukemia (B-ALL) [3]. In recent years, CAR-based therapy has demonstrated remarkable results against tumor cells. Over the last decade, FDA approved three types of CAR-T cells, namely Tisagenlecleucel (Kymriah), Axicabtagene ciloleucel (Yescarta), Brexucabtagene autoleucel (Tecartus), for some patients with relapsed or refractory leukemia and for patients with some kinds of lymphomas [4-6]. Technically, a patient's T cells are genetically engineered to express artificial receptors, CARs, to redirect $\mathrm{T}$ cells specifically toward the antigen of interest on cancer cells [7]. A CAR is a synthetic construct composed of an antigen recognition domain derived from a monoclonal antibody, a hinge region, a transmembrane domain, a co-stimulatory domain(s), and a TCR activation domain (Figure 1A). CAR gives T lymphocytes supraphysiologic properties to identify and attack the preferred target cells in a quick and robust manner $[8,9]$. When CAR interacts with the cognate tumor antigen, the activation signal transmits to $\mathrm{T}$ cells and the activated $\mathrm{T}$ cells recognize the target cells independently from HLA or MHC expression. This unique feature makes CAR-T cells a versatile therapeutic option for different patients and opens up a new avenue for adoptive immunotherapy [10]. In contrast, the TCR is an $\alpha / \beta$ heterodimer that recognizes a short peptide from the MHC products. Each $\alpha / \mathrm{b}$ subunit contains variable and constant 
region domains followed by a transmembrane region. TCR associates with a six-subunit complex called CD3 dimers, such as " $\Delta 3 \varepsilon \gamma, " ~ " \Delta 3 \varepsilon \delta$, $\alpha \nu \delta " ~ " \Delta 3 \zeta \zeta$, to initiate an intracellular signaling (Figure 1B) [11, 12].

Nevertheless, most of the CAR-based therapies lie within autologous CAR-T therapy, and very few allogeneic CAR-T treatments resulted in as promising as autologous CAR-T cells. The therapeutic efficacy of CAR-T cells may encounter critical problems because the major T-cell source is derived from patient's own peripheral blood mononuclear cells (PBMCs). These may affect the therapeutic outcomes due to some pivotal issues, including difficulty in harvesting an adequate number of $\mathrm{T}$ cells, time-consuming, and ineffective to treat patients with progressive and lethal diseases in due time [13]. Current CAR-T manufacturing platforms are costly and time-consuming. A typical autologous CAR-T cell therapy includes three main phases: (a) leukapheresis (cell isolation), (b) manufacturing, and (c) preparation and administration. These processes, from isolation to administration, takes between 2-3 weeks, depending on manufacturing methods. Thus, this required time could be too long for patients at their late stage of diseases. These hurdles in autologous CAR-T cells forced the researchers to turn to the allogeneic source of $\mathrm{T}$ lymphocytes, $\mathrm{T}$ cells derived from third-party donors. However, allogeneic CAR-T cells have confronted challenges, such as alloreactivity or graft-versus-host disease (GVHD) and human leukocyte antigen (HLA) mismatches in recipient patients [14]. Gene-editing technology, clustered regularly interspaced short palindromic repeats (CRISPR)/ CRISPRassociated protein 9 (Cas9) system has been introduced to remove such barriers; but, more investigation is required to have a clear view about genome editing technology in CAR-T cells. Allogeneic CAR-T cells, such as CRISPR-edited allogeneic CAR-T cells, are not a promising alternative option to autologous CAR-T cells, despite showing some remarkable results $[15,16]$. Therefore, a new T-cell source is needed to address the challenges in autologous and allogeneic CAR-T cells. Herein, induced pluripotent stem cells (iPSCs) seem to have a potential capacity to be a novel T-cell source for CAR-T manufacturing. This article will discuss the applicability of iPSCs in CAR-T cells and consider the challenges, manufacturing process, and perspective of CAR iPSC-derived T cells.

\section{2. iPSC Overview}

Embryonic stem cells (ESCs) and human-induced pluripotent stem cells (hiPSCs) are pluripotent stem cells (PSCs). They are similar in terms of surface marker expression, self-renewal, proliferation, feeder dependence, morphology, and in vivo teratoma formation $[17,18]$. However, subtle differences in epigenetic profiling and transcriptomic were identified $[19,20]$. PSCs generate a multitude of differentiated cells that are needed for clinical purposes and offer an alternative source of cells to regenerative medicine [21]. ESCs are derived from the inner cell mass of the blastocyst. In contrast, iPSCs are originated from different somatic cell types, such as skin, cord blood cells, bone marrow cells, urine, and peripheral blood cells [22]. In the beginning, somatic cells were introduced with Yamanaka factors, such as Oct3/4, Sox2, Klf4, and c-Myc, maintained a pluripotency status. Two of these factors, c-Myc and Klf4, showed a tumorigenic potential, which increased the risk of tumor formation upon the activation or overexpression, and consequently, they were replaced with Nanog and Lin28 [17, 18, 23]. Oct3/4 is a transcription factor whose expression controls the fate of primitive inner cell mass and governs the maintenance and regaining of stem cell pluripotency [24]. Oct3/4 is further regulated by Sox2 that governs the pluripotency, while C-Myc functions on histone acetylation for chromatin decompensation, allowing Sox 2 and Oct3/4 to access their genome loci $[25,26]$. Klf4 activates Sox2 and mediates an anti-apoptotic response for iPSCs self-renewal [27, 28]. Lin28, a highly conserved RNA-binding protein, performs as a stem cell pluripotency factor via controlling self-renewal and regulating mRNA translation, especially let-7 miRNAs [29]. Finally, Nanog arranges the transcriptional network with Oct3/4 and Sox 2 and plays as an important factor for the maintenance of the undifferentiated state of pluripotent cells [30].

Currently, somatic tissues undergo a reprogramming process using pluripotency-associated transcription factors, such as Oct3/4, Sox2, Nanog, and Lin28 [31]. The reprogrammed cells are known as human iPSCs (hiPSCs), and they can be re-introduced into patients without causing severe immune rejections [32, 33]. hiPSCs attracted tremendous attention in therapeutic purposes, including cancer treatment and regenerative medicine, providing the opportunities to study the stem cell properties and the embryonic development 
process $[34,35]$. hiPSCs pave the way for clinical application through studying the disease biology, drug screening, disease models, toxicity tests, and therapeutic purposes [36]. iPSC lines should meet some inclusion criteria set by the International Stem Cell Banking Initiative for banking purposes [37]. The suggested characteristics and features for iPSC lines include but not limited to: (i) pluripotency attitudes including positive for renewal or pluripotent markers such as Nanog, Oct3/4, TRA-1-60, TRA-1-8; (ii) detecting embryonic-like morphology; (iii) differentiation capacity both teratoma formation (in vivo) and embryoid body formation (in vitro) models; (iv) transgene-silencing following reprogramming; (v) assessment of chromosomal abnormalities by karyotyping; (vi) identity testing by short tandem repeat-PCR and DNA fingerprinting; and (vii) biological or microbial contamination essay to ensure the sterility of culture [37, 38].

\section{3. $\quad$ iPSC-derived $\mathbf{T}$ cells Manufacturing and CAR iPSC-derived T cells Generation}

The generation of CAR iPSC-derived T cells define into two main steps: (a) iPSCs generation (Figure 2) and (b) introduction of the CAR gene into iPSC-derived $\mathrm{T}$ cells. Each of which has been discussed thoroughly in the following sections.

\subsection{Principle of iPSC Generation}

\subsubsection{Somatic cell isolation}

iPSCs are produced from most somatic cells and differentiate into most target cells. Peripheral blood T lymphocytes are the possible choice of somatic cells for CAR-iPSC generation [39]. For this reason, the general platform starts from obtaining $\mathrm{T}$ cells either from autologous or allogeneic sources by leukapheresis procedures. The processed cells are then washed to discard anticoagulants or other contaminated cells. $\mathrm{T}$ cells are enriched for a specific subset of cells, such as $\mathrm{CD} 3^{+}, \mathrm{CD}^{+}, \mathrm{CD} 8^{+}, \mathrm{CD} 25^{+}$, and $\mathrm{CD} 62 \mathrm{~L}^{+} \mathrm{T}$ cells. Finally, a specific $\mathrm{T}$ cell populationcan either be used for the next step or cryopreserved for future investigation $[40,41]$.

\subsubsection{Reprogramming Methods}

$\mathrm{T}$ cell of choice is ready to reprogram through the introduction of defined transcription factors either Oct4, Sox2, Nanog, and Lin28 or Oct4, Sox2, Klf4, and c-Myc[42]. Generally, the generation of hiPSCs relies on two gene delivery methods: (a) integrativeand (b) non-integrative approaches. Integrating techniques includes $\gamma$-retroviruses and lentiviruses. Although integrative gene delivery is an efficient approach and has a stable transgene expression, it integrates into the genome of host randomly and leads to mutagenesis and tumor formation $[43,44]$. Hence, constructive techniques are required to address problems in integrative gene delivery, and meticulous consideration is needed when it comes to clinical studies. In contrast, the non-integrative strategies constitute of liposomal magnetofection, episomal vectors, adenoviral vectors, Sendai virus vectors, adeno-associated viral vectors, plasmid transfection, synthetic messenger RNA, minicircle vectors, and transposon vectors[45-53]. These delivery methods mitigate the possibility of insertional mutagenesis and transgene occurrence due to minimal DNA alterations and produce a safe iPSC line [54]. The non-integrating methods are more applicable for clinical use than that of integrating strategies.

\subsubsection{The hiPSC Characterization}

The generated hiPSCs are characterized by a set of markers that are exclusively related to their pluripotency attitudes. These markers include stage-specific-embryonic antigens (SSEA3 and SSEA4), tumor rejection antigens (Tra-1-60, Tra-1-81), and the transcription factors (Oct3/4, Sox2, and Nanog). Characterization can be done based on the surface markers (Tra-1-60, Tra-1-81, SSEA3, and SSEA4) and the intracellular markers (Oct3/4, Sox2, and Nanog) using flow cytometry assay. In addition, Immunohistochemistry is another laboratory method useful for detecting both the surface and intracellular markers in hiPSC cell lines [55-57]. Alkaline phosphatase staining is also conducted as an early marker for hiPSC establishment [58].

\subsubsection{In vitro and vivo differentiation assay}


The transduced $\mathrm{T}$ cells are cultured in an appropriate media for in vitro and vivo differentiation assay. From in vitro perspective, the iPSC colonies are cut mechanically and culture in suspension to form embryoid bodies and develop the three germ layers known as endoderm, ectoderm, and mesoderm. Each of these layers is positive for a specific marker, including beta-III tubulin for ectoderm, alpha-fetoprotein or SOX17 for endoderm, and smooth muscle actin for mesoderm [59,60]. In vivo assay evaluates the teratoma formation of hiPSCs in an immunocompromised mouse whether the undifferentiated hiPSCs are capable of forming a teratoma [61, 62].

\subsubsection{Genetic analysis}

Genetically unstable hiPSCs increase the risk of cancer or tumorigenicity and decrease the potential therapeutic use [43]. Genome stability is characterized by different techniques, including karyotype, fingerprinting, whole-genome analysis, array CGH, single nucleotide polymorphism, cancer predisposition testing, residual vector, and HLA typing [63-68]. Karyotype and fingerprinting techniques have been used widely in the genetic integrity of hiPSCs [69]. Giemsa-banding (G-banding) is a technique that produces a visible karyotype and used for chromosome counts to detect aneuploidies and karyotypically abnormal hiPSCs [70]. Besides, the fingerprinting technique analyses short tandem repeats (STR) loci to authenticate the hiPSCs and help to recognize unwanted switch or cross-contamination [71].

\subsubsection{Sterility Testing}

Cell culture undergoes sterility testing for possible contamination by bacteria, endotoxins, mycoplasma, and viruses. The most common method for bacterial or mycoplasma detection is a PCR-based technique and LAL (limulous amoebocyte lysate) assay for endotoxin verification [72].

\subsubsection{T cell differentiation from iPSCs}

T-cell development from hematopoietic stem cells (HSCs) in vivo is a complex process requiring a cascade of signals and a multitude of factors; providing the same environment and signals in vitro to induce T-cell lineage commitment for similar physiological $\mathrm{T}$ lymphocyte development is almost laborious and complex [73]. Since the differentiation pathway of iPSCs toward the hematopoietic lineage is almost the same as ESCs, T lymphocyte development from iPSCs might mimic the same pathway used in HSCs (Figure 3) [74-76]. iPSCs can be differentiated into hematopoietic cells from mesodermal cells with three in vitro methods: (1) embryoid body (EB)-based approach [77], (2) feeder cell co-culture (OP9 stromal cells derived from newborn bone marrow of the mouse calvaria and aorta-gonad-mesonephros (AGM)-derived stromal cells) [78, 79], and (3) dishes coated with extracellular matrixes (such as collagen and fibronectin) [80]. Among, OP9-DL1, a mouse bone marrow-derived stromal cell line that engineered to overexpress the Notch ligand, Delta-like ligand 1 (Dll-1), is a promising approach to differentiate iPSCs into T lymphocytes in vitro. OP9-DL1 culture system provides essential factors, such as interleukin-7, stem cell factors, and C-X-C motif chemokine ligand 12, that allows for commitment, differentiation, and proliferation of T-lineage cells derived from iPSCs [78, 81]. Although such strategies are in their preliminary investigation and cannot yet lead to efficient T-cell differentiation and desired number, they are being worked and will hopefully provide a promising system for $\mathrm{T}$ cell development.

\subsection{Principle of off-the-shelf CAR iPSC-derived T cell Generation}

The developed $\mathrm{T}$ cells from iPSCs (iPSC-derived T cells) are enriched for a specific cell population, such as $\mathrm{CD}^{+} \mathrm{T}$ cells. The pure iPSC-derived $\mathrm{T}$ cells are then activated through the interaction between their TCR or co-stimulatory receptors and $\mathrm{T}$ cell stimulation factors such as $\mathrm{mAbs}$, interleukins (IL-2, IL-7, 1L-15), anti-CD3/CD28 antibody-coated magnetic beads, soluble CD3 antibody, artificial antigen-presenting cells (K562 cell lines), plate-bound antibody, and adhesion molecules (CD2) [82, 83]. Next, there are two choices to generate off-the-shelf CAR iPSC-derived T cells. First, the CAR-Transgene and the CRISPR/Cas9 system introduce into activated iPSC-derived T cells separately. In this stage, the CAR-transgene is delivered into activated iPSC-derived T cells through either viral (lentiviral or retroviral) transduction or non-viral (electroporation of naked DNA and plasmid-based transposon/ transposase) methods. Afterward, 
the CRISPR/Cas9 system is introduced into CAR modified-T cells through one of the following ways. The use of plasmid DNA encoding the Cas9 protein and sgRNA from the same vector. The second format is to deliver the mixture of the Cas9 mRNA and the sgRNA. The last format is the use of Cas9 protein and sgRNA complex, known as ribonucleoprotein, which showed to be beneficial compared to the other two systems [84]. CAR iPSC-derived T cells are expanded by different commercial procedures using supplemental factors and cytokine supplementation [85]. Finally, CAR iPSC-derived T cells are ready to be introduced into the recipient patient through IV injection or intratumoral administration (Figure 4).

\section{Generation of T lymphocytes from iPSC Technology: A New T-cell Source}

In contrast to the remarkable success in fighting B cell malignancies, the improvement of immunotherapy towards $\mathrm{T}$ cell malignancies is far from a promising therapeutic approach. T cell malignancies are a heterogeneous group of diseases that affect the clonal growth of $\mathrm{T}$ cells at various stages of development, resulting in either T-cell leukemias or T-cell lymphomas [86]. T cell malignancies are the most common form of hematologic disorders seen in pediatric patients. T cell acute lymphoblastic leukemia (T-ALL) accounts for nearly $12 \%-15 \%$ of childhood ALL cases [87]. One of the pivotal problems in patients with T cell malignancies is the low number of normal $\mathrm{T}$ cells and proliferative exhaustion, which impede the adoptive $\mathrm{T}$ cell immunotherapy from a successful treatment. Besides, almost all the current adoptive $\mathrm{T}$ cell immunotherapies are conducted in autologous-based T cells, which are costly, laborious, time-consuming, and depend on the count and quality of the patient's T cells [88, 89]. Having an alternative source of $\mathrm{T}$ cells with optimized physiological features would greatly improve the scope of immunotherapy. To this aim, T lymphocytes can be generated from induced pluripotent stem cells [90].

In 2010, three research groups reported the reprogramming ofPBMCs with four transcription factors to produce induced pluripotent stem cells [91-93]. Staerk et al. used FUW-M2rtTA and the individual doxycyclineinducible lentiviruses encoding Oct4, Sox2, c-Myc, and Klf4to reprogram PBMCs. This system led them to an unsuccessful reprogramming, which might be due to poor penetration of the plasmid in PBMCs. To address this problem, they exerted doxycycline-inducible lentivirus encoding all four factors Oct4, Klf4, Sox2, and c-Myc from a polycistronic expression cassette. This system resulted in higher penetration efficacy and led to the generation of iPSC-derived PBMC colonies. One of the significant findings is that IL-7 plays an important role in reprogramming efficiency and cell expansion in cell culture, compared to IL-3, IL-6, GCSF, and GM-CSF. iPSC-derived PBMCs demonstrated the pluripotency markers, such as Oct4, Nanog, and Tra1-8, and displayed a normal karyotype. In vitro differentiation analysis revealed that iPSC-derived PBMC lines showed all three lineage markers, such as mesodermal, endodermal, and ectodermal. These molecular and morphological characteristics of reprogrammed PBMCs are indicative of pluripotency. Furthermore, TCR gene rearrangement detection was performed in iPSC-derived PBMCs to determine the origin of iPSC as a mature T cell. Despite negative results of TCR gene rearrangement assays in most PBMC-derived iPSC lines, one iPSC line was positive for TCR gene rearrangement, indicating the possibility of iPSC generation from human terminally differentiated circulating $\mathrm{T}$ cells [93].

Subsequently, in the same year, two other groups reported the generation of human iPSCs from peripheral blood mononuclear cells [91, 92]. Although both studies used the same transcription factors (Oct3/4, Sox2, Klf4, and c-Myc) to generate iPSC-derived PBMCs, the vectors exerted in these studies were different. Seki et al. used a temperature-sensitive mutated Sendai virus $(\mathrm{SeV})$, a non-integrating vector. This vector only replicates in the cytoplasm of target cells and does not integrate into the host genome. SeV showed that even a low sample size, $1 \mathrm{ml}$, is sufficient to infect the cell of interest. It indicated a rapid removal of residual viral genomic RNA from infected cells, signifying a promising choice to mitigate tumor formation risk associated with inactivation of tumor suppressor genes or oncogene [92]. In contrast, Loh et al. introduced the four transcription factors with integrating lentiviruses and found a satisfactory result. Lentiviral vectors are integrating vectors, meaning that viral DNA translocates into the nucleus and integrates into the host genome. This process of integration requires more time to produce the interest results, compared to non-integrating vectors [91]. More importantly, both studies demonstrated the possibility of hiPSC generation from periph- 
eral blood cells. Of note, iPSC-derived PBMCs had human embryonic stem cells (ESCs)-like characteristics, including morphology, pluripotency-associated transcription factors, DNA methylation, differentiation potential, expression of surface antigens, and detection of all three embryonic germ layers [91, 92]. Likewise, Netsrithong et al. have generated two iPSC lines, MUSIi011-A and MUSIi011-B, from peripheral blood T lymphocytes [94]. Further success can be seen in reprogramming melanoma tumor-infiltrating lymphocytes (TILs) containing patient-specific tumor-reactive repertoire. iPSC-derived TILs demonstrated all the features of embryonic stem cells and had the capability to differentiate in vitro and in vivo. Interestingly, this study showed that the $\mathrm{SeV}$ vector is able to generate iPSCs from terminally differentiated and exhausted TILs expressing a high level of inhibitory receptors, such as PD-1. However, a low reprogramming efficiency in TILs was seen, which might be due to the exhausted or differentiation status of the cells. These iPSCs can produce many phenotypically defined, expandable, specific, and functional polyclonal $\mathrm{T}$ cells with the same specific-TCR for cancer immunotherapy [95]. In consistent with these studies, Nagano et al. further corroborated that the development of T cells from iPSC technology is feasible and can be applied for large-scale $\mathrm{T}$ cell generation [90].

CTLs detect antigenic peptides presented by MHC class I expressed by infected or malignant cells. These cells, by their direct contact or in a TCR-dependent manner, attack the target cells and provide a safe harbor to other cells. Interestingly, CTLs could also destroy tumor cells through an MHC-independent manner attacking autologous tumor cells without affecting other cells within the area [96, 97]. Cancer immunotherapy using transfer of TCR genes [98, 99] or adoptive transfer of CTLs [100, 101] has been facing an important problem in harvesting enough antigen-specific CTLs for therapy. Maeda et al. used iPSC technology to clone and expand CTLs in an adequate number for therapeutic purposes. They harvested WT1-specific CTLs from healthy volunteers. WT1 antigen is expressed by acute myeloid leukemia (AML) cells. For the establishment of iPSC lines, SeV vectors encoding Yamanaka factors and SV40 were introduced to the WT1-specific CTLs. Despite a successful transfection and establishment of three WT1-iPSC lines with normal karyotype and ESCs-like characteristics, this study shed light on other important features of CTLs. When iPSCs are generated from WT1-specific CTLs, they inherited rearranged TCR genes-specific for WT1, highlighting the same expression of WT1-specific TCRs in iPSCs. It is crucial to determine

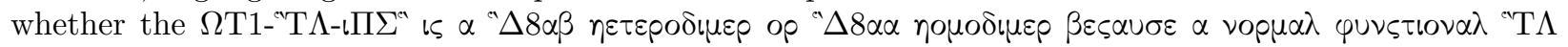

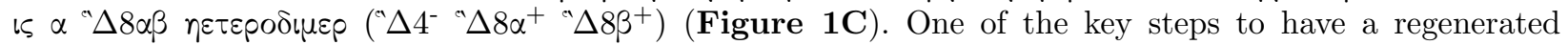
$\mathrm{CD} 8 \alpha \beta \mathrm{T}$ cell is to use double-positive $\mathrm{CD} 4^{+} / \mathrm{CD} 8^{+} \mathrm{T}$ cells and remove double-negative $\mathrm{T}$ cells in mixed cultures because double-negative cells kill $\mathrm{CD} 4^{+} / \mathrm{CD} 8^{+} \mathrm{T}$ cells. Moreover, WT1-CTL-iPSCs demonstrated satisfactory outcomes regarding safety issues and anti-tumor activities in mice with leukemia [74]. iPSCderived T cells store a pre-rearranged TCR gene in the genome that stemmed from antigen-specific CD ${ }^{+}$ $\mathrm{T}$ cells. Kaneko et al. revealed the role of RAG1 (recombination activating gene1) and RAG2 in both $\operatorname{TCR} \alpha$ and TCR $\beta$ rearrangement during thymopoiesis. The additional TCR $\alpha$ rearrangement at CD4/CD 8 double-positive stage during iPSCs differentiation to T cells is associated with antigen-specificity loss. This extra TCR $\alpha$ rearrangement may lead to an off-target effect and reduce the stability of the same TCR as it was present in the original T cell clone. They used the CRISPR/Cas9 system to knock-out RAG2 during the iPSCs differentiation to CD8 $\alpha \beta \mathrm{T}$ cells. This strategy led them to maintain the antigen-specificity of TCRs with the same avidity and affinity in iPSC-derived CD $8 \alpha \beta \mathrm{T}$ cells. Meanwhile, the anti-tumor activity of $\mathrm{RAG}^{-/-}$iPSC-derived CD8$\alpha \beta$ T cells was examined both in vitro and in vivo conditions, which successfully decreased the tumor growth and increased the survival of treated NSG mice. This study provided a new approach to acquire a great number of TCR-specific T cells from iPSCs with the same potent anti-tumor activity, which would be beneficial for efficient and safe immunotherapy (Table 1) [75].

\section{Generation of CAR-T cells from iPSC Technology}

In this decade, CAR-T cell therapy has been increasingly carried out in clinical settings worldwide. The data from Clinicaltrails.gov demonstrated that over 650 CAR-T-related studies were initiated around the world.

The T cells currently used for CAR-T development are predominantly derived from patient's PBMCs, rarely 
from umbilical cord blood and less from third-party healthy donors [102]. It is well-defined that the current manufacturing process of CAR-T cells is laborious and intensive, and it requires a carefully selecting donors with adequate autologous $\mathrm{T}$ cells. This labor-intensive generation of T-cell lines from the patients consumes time and may not be applied to those who have insufficient $\mathrm{T}$ cells. These include HIV-infected or $\mathrm{T}$ cell leukemia patients and leukemia patients with relapse after allogeneic hematopoietic cell transplantation and those the use of allogeneic donor lymphocyte infusions is challenging [103-106]. Having a rapid access to unlimited T-cell sources with optimized physiological features would remarkably improve the success of genetically engineered-T cells. In this case, genetic engineering of iPSC-derived T cells with CARs would be a promising strategy to harvest iPSC-derived $\mathrm{T}$ cells unlimitedly and genetically engineered them to generate phenotypically defined, expandable, and functional $\mathrm{T}$ cells for therapeutic purposes. Themeli et al. have isolated PBMCs from a healthy donor and transduced them by two retroviral vectors, each encoding two of the reprogramming factors (Oct3, Sox2, Klf4, and c-Myc). The transduced T cells under standard laboratory conditions and care resulted in T-iPSC colonies, and subsequently, were introduced with a lentiviral vector encoding CD19-28z CAR. The transduced iPSCs are then differentiated into T cells that express both the CAR and an endogenous TCR. Findings revealed a successful generation of CD19-T-iPSC lines for targeting CD19 antigen in a xenograft mouse model of Raji human CD19+ Burkitt lymphoma cells. Laboratory analysis showed that CD19 CAR-iPSC-derived T cells had a low expression of exhaustion markers, such as PD1, CTLA-4, and LAG3. In vivo cytotoxic assay displayed a potent anti-tumor activity where the tumor growth was delayed and led to complete tumor regression. Of note, this study generated iPSC-derived T cells with endogenous TCR, which signifies the possibility of alloreactivity involving transplant rejection and GVHD. Phenotypic profiling indicated that the generated T cells from iPSCs are CD $8 \alpha^{+} \mathrm{CD} 8 \beta^{-}$, meaning that these lymphoid cells possibly originated from a fetal cell-like hematopoietic stem cell intermediate committed to innate-like lymphopoiesis rather than a CD8 $\alpha \beta$ heterodimer (CD4- CD8 $\alpha^{+}$CD8 $\beta^{+}$) T cell [35]. This study was the first to report the genetic manipulation of human iPSC-derived T cells with artificial receptors, CARs, with therapeutic potential.

\section{6. iPSC-derived T cell on Its Way to Off-the-shelf Product: Challenges and Solutions}

It is well-established that autologous CAR-T cell therapy is more efficient, persistent, and safe with no allogeneic reaction for cancer patients [5, 107, 108]. However, autologous CAR-T cell therapy may not be as effective as it should be in some critical conditions, and it poses complexity and difficulties for researchers and clinicians. The concerns that autologous CAR-T cells could bring are included but not limited to the following limitations. (I) CAR-T cell manufacturing takes nearly 2-3 weeks; during this period, patients may diagnose with rapid progression of disease requiring immediate attention, and the possibility of laboratory fiasco in the manufacturing process may prevent the patients from receiving an appropriate dose of CAR-T cells [4, 109]. (II) CAR-T cells from autologous source are produced in a single batch with limited quantity, meaning that redosing of CAR-T cells may not be applicable for some patients [110]. (III) collecting T cells from cancer patients with a prior line of treatments increase the chance of isolating dysfunctional $\mathrm{T}$ cells due to disease burden or previous use of heavy medications, such as chemotherapy drugs [111, 112]. (IV) leukapheresis products from cancer patients, especially leukemia patients, may contain aberrant $\mathrm{T}$ cells, and CAR gene may be unintentionally introduced into malignant $\mathrm{T}$ cells to express $\mathrm{CAR}$ protein. This phenomenon leads to resistance through masking of the CD19 epitope [113]. (V) CAR-T cell efficacy is associated with functional capacity of autologous $\mathrm{T}$ cells. It is essential to determine the cell subset, whether it is effector memory $\mathrm{T}$ cells or short-living effector T cells, or central memory T cells $[114,115]$. Although autologous CAR-T cells have revolutionized the therapeutic landscape in oncology, the use of allogeneic CAR-T cells from thirdparty donors has several distinct advantages over autologous approaches [116]. These superiorities include pre-prepared CAR-T cell products for emergency use, more high-quality products, applicable to develop two different CAR-T cells for combination therapy, suitable for redosing purposes, and reduce the cost of the manufacturing process. However, allogeneic CAR-T cells are not deprived of problems. They may cause life-threatening GVHD and may be rapidly eliminated by the host immune system, reducing the anti-tumor activity and therapeutic outcomes [117].

iPSC lines provide an unlimited source of $\mathrm{T}$ cells for therapeutic purposes, but these iPSC-derived $\mathrm{T}$ cells are 
not considered off-the-shelf products. They cannot be applied for third-party patients due to the presence of endogenous TCR or human leukocyte antigen (HLA) mismatch [35]. The most common TCR-associated adverse effect is GVHD, in which the donor T cells identify the host antigens as foreign, and subsequently, destroy them. GVHD risk depends on several factors. The most important one is the HLAs, which are highly polymorphic and variable [118]. Among, HLA class I (HLA-A, -B, and -C) and HLA class II (HLA-DP, -DQ, and -DR) are the most important molecules involving in immune rejection. The former molecule is expressed by all nucleated cells and present the processed antigens inside the infected cells to CD8 ${ }^{+}$cytotoxic T cells. In contrast, the latter present antigens outside the cells and is expressed by antigen-presenting cells, such as dendritic cells and macrophages, to activate $\mathrm{CD} 4^{+} \mathrm{T}$ cells for a further adaptive immune response [119]. $X u$ et al. developed immuno-compatible iPSCs from third-party donors using the genome editing technology, CRISPR/Cas9. First, they converted HLA heterogenous iPSCs into HLA pseudo-homozygous iPSCs, by knocking out a single allele of HLA-A (A1) and HLA-B (B7) simultaneously. The HLA-AB- iPSCs were co-cultured with $\mathrm{CD} 8^{+} \mathrm{T}$ cells. They remarkably did not stimulate $\mathrm{CD} 8^{+} \mathrm{T}$ cell proliferation and could escape from $\mathrm{T}$ cell cytolytic activity, meaning no HLA mismatch between $\mathrm{CD} 8^{+} \mathrm{T}$ cells and HLA-AB${ }^{-}$ iPSCs. This finding strongly suggested that homozygous iPSCs can be generated from HLA heterozygous healthy individuals (third-party donors), which would provide an unlimited source of HLA homozygous iPSCs for therapeutic application, especially for CAR-T cell therapy. In addition to HLA-A/B knockout, HLA-C was further removed in iPSCs, resulting in triple knockout iPSCs $\left(\mathrm{HLA}_{-} \mathrm{A}^{-}, \mathrm{B}^{-}\right.$, and $\left.\mathrm{C}^{-}\right)$. $\mathrm{HLA}^{-\mathrm{ABC}^{-}}$ iPSCs could escape from T cell cytolytic activity. But, the strategy of HLA-C depletion is not interesting and cannot be used for a large population and may raise the concern of NK cell response due to lack of MHC-I on iPSCs; therefore, the HLA-C7 was retained in $\mathrm{HLA}^{-\mathrm{AB}^{-}}{ }^{\mathrm{iPSC}}$. Interestingly, the $\mathrm{HLA}^{-\mathrm{AB}^{-} \mathrm{C}^{+}}$ iPSCs demonstrated outstanding results both in vitro and vivo, where they evade the NK cell activity and survived against both $\mathrm{T}$ and NK cells cytotoxic activities, respectively. These data proposed that HLA-C is a pivotal factor for suppressing or evading the NK cell activity. Besides, $\mathrm{HLA}-\mathrm{AB}^{-} \mathrm{C}^{+}{ }^{+}$iPSCs were further manipulated through depletion of MHC class II trans-activator gene encoding HLA-II because CD4 ${ }^{+}$T cells recognize HLA-II and secrete cytokines to accumulate a wide range of immune cells. This provides a better donor-host matching for therapeutic and clinical applications [120]. When iPSCs are considered for T cell generation as an unlimited source for off-the-shelf CAR-T cell development, endogenous TCR expression and HLA mismatch should be addressed. This study clearly showed the possibility and feasibility of genetic manipulation in iPSC lines; therefore, depletion of endogenous TCR and HLAs in iPSCs are crucial for the development of off-the-shelf iPSC-derived T cells.

\section{Clinical Translation of Human CAR iPSC-derived T cells: Future Perspective}

Over the last two decades, iPSCs and CAR-T cells have opened up a new avenue for regenerative medicine and cell-based therapy, respectively. Since their discoveries, a wide range of protocols and studies have been developed. Both iPSC-derived cells and CAR-T cells have been used in a multitude of small and large pre-clinical and clinical trials to treat a variety of diseases. The use of iPSC-derived T cells for CAR-T cell generation has just begun and is in a preliminary stage of development. Pre-clinical studies showed the feasibility and safety of iPSC-derived T cells and displayed them as a novel T-cell source for CAR-T cell development. The combination of these new technologies, CAR-T cell and iPSC, has not been investigated in clinical trials; therefore, the clinical use of CAR iPSC-derived T cells requires thorough consideration. This section discussed the hurdles and perspective to clinical translation of CAR iPSC-derived T cells, including major clinical requirements, product manufacturing, quality standard, off-the-shelf product, timelines, and side effects.

First, it is important to develop a controlled, robust, and reproducible manufacturing platform adherent to Good Manufacturing Practice (GMP). More Pre-clinical studies, possibly under Good Laboratory Practice (GLP), is required to implement a defined cultured system and equipment because undefined media or materials bring a risk of contamination and may alter the phenotype or function of the cells. Pre-clinical studies provide an opportunity to assess the off-target effects, feasibility, product safety, and the potential in vivo challenges. Due to the complexity of iPSC and CAR-T cell generation, studies need to comply Current GMP (cGMP) regulations to provide sufficient evidence of safety, identity, potency, and purity 
of the products. It is well-established that the identity of iPSC and CAR-T cell products is commonly characterized by defined markers and gene expression. Therefore, having a predefined protocol to evaluate or analyze the features of iPSC and CAR-T cell products would enhance the success of the manufacturing process and therapeutic outcomes. For example, the most important post-treatment safety concern for iPSCs is the formation of either malignant teratoma or benign teratoma [121]. Thus, it is crucial to ensure that the infused products have a low risk of tumorigenicity.

More importantly, by the advent of iPSC-derived T cells as a new T-cell source, several challenges need to be pre-clinically addressed before embarking on multicentral clinical trials. First, the physiological function and phenotypic maturity of iPSC-derived T cells have to be characterized, as well as the anti-tumor activity or cytokine secretion compared to physiological T lymphocytes. Despite an established manufacturing protocol for clinical scale production, further assessment concerning the potential risk of tumorigenesis and differentiation capacity need to be considered [122]. Furthermore, there may be genetic and epigenetic variations among different iPSC and CAR-T products. The key factors, including DNA methylation and histone modification, may alter the phenotype of products and may lead to mitochondrial mutations, chromosomal aberrations, epigenetic variance, and genetic diversification. Hence, culture conditions and manufacturing strategies must be optimized to mitigate such phenomena [123-125].

Breakthroughs in genome editing technology paved the way to generate CAR and off-the-shelf iPSC-derived $\mathrm{T}$ cells with a robust anti-tumor response, limited off-target effect, more remarkable persistence, better homing or trafficking, and more compatible to histocompatibility barriers [35, 120]. Encouragingly, iPSCderived $\mathrm{T}$ cells have the potential to become off-the-shelf $\mathrm{T}$ cells using the CRISPR/Cas9 system. The allogeneic iPSC-derived T cells undergo a genome editing process to be deprived of TCR and HLAs. The resulted T cells would be negative for TCR and HLA proteins and could be used for different third-party patients [120]. However, this approach has not been investigated thoroughly and is in early stages; therefore, for clinical purposes, several pivotal issues, such as off-target effect, feasibility, safety, and manufacturing approach, have to be investigated.

\section{Questions remained unanswered}

It is essential to detect the most promising somatic cells as a source for iPSC development. For example, studies to shed light on which of the cell types within the PBMCs are more capable of becoming iPSCs are highly recommended. Since the concept of iPSC generation in this article is for CAR-T cell development, does the original cell source, iPSC-derived cell, play a role in the function of differentiated CAR-T cells? Can cells other than PBMCs be used to generate functional T cells? Still there is no evidence that supports the use of other cell source for T cell generation as a better option than PBMCs. If the goal of using iPSCderived cells is their ability to replace endogenous $\mathrm{T}$ cells, then what challenges does the use of PBMCs pose for implementing CAR iPSC-derived T cells into the clinic?

Do iPSC-derived CAR-T cells offer any advantages over traditional CAR-T cells other than the potential to use non- $T$ cells as a cell source? For example, do these cells work better against solid tumors or hematologic malignancies? Such studies have not been performed yet and can be considered as a future direction to this filed.

\section{Conclusion}

The combination of iPSC and CAR-Technologies provides an extraordinary opportunity to oncology and greatly facilitates cell-based therapy for cancer patients. This system offers researchers and clinicians efficient and safe ways of generating iPSC-derived $\mathrm{T}$ cells as an unlimited T-cell source for therapeutic purposes. Although the pre-clinical and clinical studies concerning the combination of iPSC and CAR-Technologies are not sufficient, these pioneer studies that we described here shed light on the applicability and feasibility of iPSC-derived $\mathrm{T}$ cells for CAR-T development. CAR iPSC-derived $\mathrm{T}$ cells offer that a novel CAR-T cell is on its way to clinical use. 


\section{Acknowledgments}

The author would like to acknowledge the reviewers for their helpful and constructive comments on this manuscript.

\section{Conflict of interest}

The author stated that there is no conflict of interest

\section{Funding}

No financial support was received

\section{Ethic approval}

Not Applicable

\section{References}

1. Wang Z, Cao YJ. Adoptive Cell Therapy Targeting Neoantigens: A Frontier for Cancer Research. Frontiers in Immunology. 2020;11(176).

2. Rohaan MW, Wilgenhof S, Haanen J. Adoptive cellular therapies: the current landscape. Virchows Arch. 2019;474(4):449-61.

3. Milone MC, Bhoj VG. The pharmacology of T cell therapies. Molecular Therapy-Methods \& Clinical Development. 2018;8:210-21.

4. Maude SL, Laetsch TW, Buechner J, Rives S, Boyer M, Bittencourt H, et al. Tisagenlecleucel in Children and Young Adults with B-Cell Lymphoblastic Leukemia. N Engl J Med. 2018;378(5):439-48.

5. Neelapu SS, Locke FL, Bartlett NL, Lekakis LJ, Miklos DB, Jacobson CA, et al. Axicabtagene Ciloleucel CAR-T-Cell Therapy in Refractory Large B-Cell Lymphoma. N Engl J Med. 2017;377(26):253144.

6. Wang M, Munoz J, Goy A, Locke FL, Jacobson CA, Hill BT, et al. KTE-X19 CAR-T-Cell Therapy in Relapsed or Refractory Mantle-Cell Lymphoma. N Engl J Med. 2020;382(14):1331-42.

7. Srivastava S, Riddell SR. Chimeric Antigen Receptor T Cell Therapy: Challenges to Bench-toBedside Efficacy. J Immunol. 2018;200(2):459-68.

8. Yang Y, Jacoby E, Fry TJ. Challenges and opportunities of allogeneic donor-derived CAR-T cells. Curr Opin Hematol. 2015;22(6):509-15.

9. $\quad$ Sadeqi Nezhad M, Seifalian A, Bagheri N, Yaghoubi S, Karimi MH, Adbollahpour-Alitappeh M. Chimeric Antigen Receptor Based Therapy as a Potential Approach in Autoimmune Diseases: How Close Are We to the Treatment? Frontiers in Immunology. 2020;11(3062).

10. Abreu TR, Fonseca NA, Gonçalves N, Moreira JN. Current challenges and emerging opportunities of CAR-T cell therapies. Journal of Controlled Release. 2020;319:246-61.

11. Birnbaum ME, Berry R, Hsiao Y-S, Chen Z, Shingu-Vazquez MA, Yu X, et al. Molecular architecture of the $\alpha \beta \mathrm{T}$ cell receptor-CD3 complex. Proceedings of the National Academy of Sciences. 2014;111(49):17576-81.

12. Rudolph MG, Stanfield RL, Wilson IA. How TCRs bind MHCs, peptides, and coreceptors. Annu Rev Immunol. 2006;24:419-66.

13. Wang X, Rivière I. Clinical manufacturing of CAR-T cells: foundation of a promising therapy. Mol Ther Oncolytics. 2016;3:16015. 
14. Townsend MH, Bennion K, Robison RA, O'Neill KL. Paving the way towards universal treatment with allogenic T cells. Immunologic Research. 2020:1-8.

15. Li C, Mei H, Hu Y. Applications and explorations of CRISPR/Cas9 in CAR-T-cell therapy. Briefings in functional genomics. 2020;19(3):175-82.

16. Liu J, Zhou G, Zhang L, Zhao Q. Building Potent Chimeric Antigen Receptor T Cells With CRISPR Genome Editing. Frontiers in immunology. 2019;10:456-.

17. Takahashi K, Tanabe K, Ohnuki M, Narita M, Ichisaka T, Tomoda K, et al. Induction of pluripotent stem cells from adult human fibroblasts by defined factors. Cell. 2007;131(5):861-72.

18. Yu J, Vodyanik MA, Smuga-Otto K, Antosiewicz-Bourget J, Frane JL, Tian S, et al. Induced pluripotent stem cell lines derived from human somatic cells. Science. 2007;318(5858):1917-20.

19. Kim K, Zhao R, Doi A, Ng K, Unternaehrer J, Cahan P, et al. Donor cell type can influence the epigenome and differentiation potential of human induced pluripotent stem cells. Nat Biotechnol. 2011;29(12):1117-9.

20. Parrotta E, De Angelis MT, Scalise S, Candeloro P, Santamaria G, Paonessa M, et al. Two sides of the same coin? Unraveling subtle differences between human embryonic and induced pluripotent stem cells by Raman spectroscopy. Stem Cell Res Ther. 2017;8(1):271.

21. Wattanapanitch M. Recent Updates on Induced Pluripotent Stem Cells in Hematological Disorders. Stem Cells Int. 2019;2019:5171032.

22. Liu G, David BT, Trawczynski M, Fessler RG. Advances in Pluripotent Stem Cells: History, Mechanisms, Technologies, and Applications. Stem Cell Rev Rep. 2020;16(1):3-32.

23. Takahashi K, Yamanaka S. Induction of Pluripotent Stem Cells from Mouse Embryonic and Adult Fibroblast Cultures by Defined Factors. Cell. 2006;126(4):663-76.

24. Shi G, Jin Y. Role of Oct4 in maintaining and regaining stem cell pluripotency. Stem Cell Res Ther. 2010;1(5):39.

25. Kim D, Kim C-H, Moon J-I, Chung Y-G, Chang M-Y, Han B-S, et al. Generation of human induced pluripotent stem cells by direct delivery of reprogramming proteins. Cell stem cell. 2009;4(6):472-6.

26. Scheper W, Copray S. The molecular mechanism of induced pluripotency: a two-stage switch. Stem Cell Rev Rep. 2009;5(3):204-23.

27. Nandan MO, Yang VW. The role of Krüppel-like factors in the reprogramming of somatic cells to induced pluripotent stem cells. Histol Histopathol. 2009;24(10):1343-55.

28. Niwa H, Ogawa K, Shimosato D, Adachi K. A parallel circuit of LIF signalling pathways maintains pluripotency of mouse ES cells. Nature. 2009;460(7251):118-22.

29. Shyh-Chang N, Daley GQ. Lin28: primal regulator of growth and metabolism in stem cells. Cell stem cell. 2013;12(4):395-406.

30. Rodda DJ, Chew JL, Lim LH, Loh YH, Wang B, Ng HH, et al. Transcriptional regulation of nanog by OCT4 and SOX2. J Biol Chem. 2005;280(26):24731-7.

31. Wu Y, Zhang Y, Mishra A, Tardif SD, Hornsby PJ. Generation of induced pluripotent stem cells from newborn marmoset skin fibroblasts. Stem Cell Res. 2010;4(3):180-8.

32. $\quad \mathrm{Liu} \mathrm{X}, \mathrm{Li} \mathrm{W}, \mathrm{Fu} \mathrm{X}, \mathrm{Xu}$ Y. The Immunogenicity and Immune Tolerance of Pluripotent Stem Cell Derivatives. Frontiers in immunology. 2017;8:645-.

33. Yamanaka S. Pluripotent Stem Cell-Based Cell Therapy-Promise and Challenges. Cell Stem Cell. 2020;27(4):523-31. 
34. Li Y, Hermanson DL, Moriarity BS, Kaufman DS. Human iPSC-Derived Natural Killer Cells Engineered with Chimeric Antigen Receptors Enhance Anti-tumor Activity. Cell Stem Cell. 2018;23(2):18192.e5.

35. Themeli M, Kloss CC, Ciriello G, Fedorov VD, Perna F, Gonen M, et al. Generation of tumortargeted human $\mathrm{T}$ lymphocytes from induced pluripotent stem cells for cancer therapy. Nat Biotechnol. 2013;31(10):928-33.

36. Fernandez TdS, de Souza Fernandez C, Mencalha AL. Human Induced Pluripotent Stem Cells from Basic Research to Potential Clinical Applications in Cancer. BioMed Research International. 2013;2013:430290.

37. Crook JM, Hei D, Stacey G. The International Stem Cell Banking Initiative (ISCBI): raising standards to bank on. In Vitro Cell Dev Biol Anim. 2010;46(3-4):169-72.

38. Huang C-Y, Liu C-L, Ting C-Y, Chiu Y-T, Cheng Y-C, Nicholson MW, et al. Human iPSC banking: barriers and opportunities. Journal of biomedical science. 2019;26(1):87-.

39. Vizcardo R, Masuda K, Yamada D, Ikawa T, Shimizu K, Fujii S, et al. Regeneration of human tumor antigen-specific T cells from iPSCs derived from mature CD8(+) T cells. Cell Stem Cell. 2013;12(1):31-6.

40. Tumaini B, Lee DW, Lin T, Castiello L, Stroncek DF, Mackall C, et al. Simplified process for the production of anti-CD19-CAR-engineered T cells. Cytotherapy. 2013;15(11):1406-15.

41. Wang X, Rivière I. Clinical manufacturing of CAR-T cells: foundation of a promising therapy. Molecular Therapy - Oncolytics. 2016;3:16015.

42. Nishimura T, Kaneko S, Kawana-Tachikawa A, Tajima Y, Goto H, Zhu D, et al. Generation of rejuvenated antigen-specific $\mathrm{T}$ cells by reprogramming to pluripotency and redifferentiation. Cell Stem Cell. 2013;12(1):114-26.

43. Ben-David U, Benvenisty N. The tumorigenicity of human embryonic and induced pluripotent stem cells. Nature Reviews Cancer. 2011;11(4):268-77.

44. Blelloch R, Venere M, Yen J, Ramalho-Santos M. Generation of induced pluripotent stem cells in the absence of drug selection. Cell stem cell. 2007;1(3):245-7.

45. Ban H, Nishishita N, Fusaki N, Tabata T, Saeki K, Shikamura M, et al. Efficient generation of transgene-free human induced pluripotent stem cells (iPSCs) by temperature-sensitive Sendai virus vectors. Proc Natl Acad Sci U S A. 2011;108(34):14234-9.

46. Miyoshi N, Ishii H, Nagano H, Haraguchi N, Dewi DL, Kano Y, et al. Reprogramming of mouse and human cells to pluripotency using mature microRNAs. Cell Stem Cell. 2011;8(6):633-8.

47. Narsinh KH, Jia F, Robbins RC, Kay MA, Longaker MT, Wu JC. Generation of adult human induced pluripotent stem cells using nonviral minicircle DNA vectors. Nat Protoc. 2011;6(1):78-88.

48. Sohn YD, Somasuntharam I, Che PL, Jayswal R, Murthy N, Davis ME, et al. Induction of pluripotency in bone marrow mononuclear cells via polyketal nanoparticle-mediated delivery of mature microRNAs. Biomaterials. 2013;34(17):4235-41.

49. Stadtfeld M, Nagaya M, Utikal J, Weir G, Hochedlinger K. Induced pluripotent stem cells generated without viral integration. Science. 2008;322(5903):945-9.

50. Warren L, Manos PD, Ahfeldt T, Loh YH, Li H, Lau F, et al. Highly efficient reprogramming to pluripotency and directed differentiation of human cells with synthetic modified mRNA. Cell Stem Cell. 2010;7(5):618-30.

51. Yusa K, Rad R, Takeda J, Bradley A. Generation of transgene-free induced pluripotent mouse stem cells by the piggyBac transposon. Nat Methods. 2009;6(5):363-9. 
52. Zhou H, Wu S, Joo JY, Zhu S, Han DW, Lin T, et al. Generation of induced pluripotent stem cells using recombinant proteins. Cell Stem Cell. 2009;4(5):381-4.

53. Zhou W, Freed CR. Adenoviral gene delivery can reprogram human fibroblasts to induced pluripotent stem cells. Stem Cells. 2009;27(11):2667-74.

54. Haridhasapavalan KK, Borgohain MP, Dey C, Saha B, Narayan G, Kumar S, et al. An insight into non-integrative gene delivery approaches to generate transgene-free induced pluripotent stem cells. Gene. 2019;686:146-59.

55. Abujarour R, Valamehr B, Robinson M, Rezner B, Vranceanu F, Flynn P. Optimized surface markers for the prospective isolation of high-quality hiPSCs using flow cytometry selection. Scientific reports. 2013;3:1179-.

56. Bharathan SP, Manian KV, Aalam SMM, Palani D, Deshpande PA, Pratheesh MD, et al. Systematic evaluation of markers used for the identification of human induced pluripotent stem cells. Biol Open. 2017;6(1):100-8.

57. Paik EJ, O'Neil AL, Ng S-Y, Sun C, Rubin LL. Using intracellular markers to identify a novel set of surface markers for live cell purification from a heterogeneous hIPSC culture. Scientific Reports. 2018;8(1):804.

58. Singh U, Quintanilla RH, Grecian S, Gee KR, Rao MS, Lakshmipathy U. Novel live alkaline phosphatase substrate for identification of pluripotent stem cells. Stem cell reviews and reports. 2012;8(3):1021-9.

59. Kumazaki T, Kurata S, Matsuo T, Mitsui Y, Takahashi T. Establishment of human induced pluripotent stem cell lines from normal fibroblast TIG-1. Hum Cell. 2011;24(2):96-103.

60. Secher JO, Ceylan A, Mazzoni G, Mashayekhi K, Li T, Muenthaisong S, et al. Systematic in vitro and in vivo characterization of Leukemia-inhibiting factor- and Fibroblast growth factor-derived porcine induced pluripotent stem cells. Mol Reprod Dev. 2017;84(3):229-45.

61. Ito E, Miyagawa S, Takeda M, Kawamura A, Harada A, Iseoka H, et al. Tumorigenicity assay essential for facilitating safety studies of hiPSC-derived cardiomyocytes for clinical application. Scientific Reports. 2019;9(1):1881.

62. Xiang M, Lu M, Quan J, Xu M, Meng D, Cui A, et al. Direct in vivo application of induced pluripotent stem cells is feasible and can be safe. Theranostics. 2019;9(1):290-310.

63. Elliott AM, Elliott KA, Kammesheidt A. High resolution array-CGH characterization of human stem cells using a stem cell focused microarray. Mol Biotechnol. 2010;46(3):234-42.

64. Jang Y, Choi J, Park N, Kang J, Kim M, Kim Y, et al. Development of immunocompatible pluripotent stem cells via CRISPR-based human leukocyte antigen engineering. Exp Mol Med. 2019;51(1):111.

65. Nazareth EJP, Ostblom JEE, Lücker PB, Shukla S, Alvarez MM, Oh SKW, et al. Highthroughput fingerprinting of human pluripotent stem cell fate responses and lineage bias. Nature methods. 2013;10(12):1225-31.

66. Popp B, Krumbiegel M, Grosch J, Sommer A, Uebe S, Kohl Z, et al. Need for high-resolution Genetic Analysis in iPSC: Results and Lessons from the ForIPS Consortium. Scientific Reports. 2018;8(1):17201.

67. Quinlan AR, Boland MJ, Leibowitz ML, Shumilina S, Pehrson SM, Baldwin KK, et al. Genome sequencing of mouse induced pluripotent stem cells reveals retroelement stability and infrequent DNA rearrangement during reprogramming. Cell stem cell. 2011;9(4):366-73.

68. Ramos-Mejía V, Montes R, Bueno C, Ayllón V, Real PJ, Rodríguez R, et al. Residual expression of the reprogramming factors prevents differentiation of iPSC generated from human fibroblasts and cord 
blood CD34+ progenitors. PLoS One. 2012;7(4):e35824.

69. Taapken SM, Nisler BS, Newton MA, Sampsell-Barron TL, Leonhard KA, McIntire EM, et al. Karyotypic abnormalities in human induced pluripotent stem cells and embryonic stem cells. Nature Biotechnology. 2011;29(4):313-4.

70. Dekel-Naftali M, Aviram-Goldring A, Litmanovitch T, Shamash J, Reznik-Wolf H, Laevsky I, et al. Screening of human pluripotent stem cells using CGH and FISH reveals low-grade mosaic aneuploidy and a recurrent amplification of chromosome 1q. European Journal of Human Genetics. 2012;20(12):1248-55.

71. Sarafian R, Morato-Marques M, Borsoi J, Pereira LV. Monitoring cell line identity in collections of human induced pluripotent stem cells. Stem Cell Res. 2018;28:66-70.

72. Sullivan S, Stacey GN, Akazawa C, Aoyama N, Baptista R, Bedford P, et al. Quality control guidelines for clinical-grade human induced pluripotent stem cell lines. Regen Med. 2018;13(7):859-66.

73. La Motte-Mohs RN, Herer E, Zúñiga-Pflücker JC. Induction of T-cell development from human cord blood hematopoietic stem cells by Delta-like 1 in vitro. Blood. 2005;105(4):1431-9.

74. Maeda T, Nagano S, Ichise H, Kataoka K, Yamada D, Ogawa S, et al. Regeneration of CD8 $\alpha \beta$ T Cells from T-cell-Derived iPSC Imparts Potent Tumor Antigen-Specific Cytotoxicity. Cancer Res. 2016;76(23):6839-50.

75. Minagawa A, Yoshikawa T, Yasukawa M, Hotta A, Kunitomo M, Iriguchi S, et al. Enhancing T Cell Receptor Stability in Rejuvenated iPSC-Derived T Cells Improves Their Use in Cancer Immunotherapy. Cell Stem Cell. 2018;23(6):850-8.e4.

76. Themeli M, Kloss CC, Ciriello G, Fedorov VD, Perna F, Gonen M, et al. Generation of tumortargeted human $\mathrm{T}$ lymphocytes from induced pluripotent stem cells for cancer therapy. Nature biotechnology. 2013;31(10):928-33.

77. Kim SJ, Kim BS, Ryu SW, Yoo JH, Oh JH, Song CH, et al. Hematopoietic differentiation of embryoid bodies derived from the human embryonic stem cell line SNUhES3 in co-culture with human bone marrow stromal cells. Yonsei Med J. 2005;46(5):693-9.

78. Chen X, Lei F, Wang L, Xiong X, Song J. Generation of Tumor Antigen-Specific Cytotoxic T Lymphocytes from Pluripotent Stem Cells. Methods Mol Biol. 2019;1884:43-55.

79. Weisel KC, Gao Y, Shieh J-H, Moore MAS. Stromal cell lines from the aorta-gonadomesonephros region are potent supporters of murine and human hematopoiesis. Experimental Hematology. 2006;34(11):1505-16.

80. Campbell A, Wicha MS, Long M. Extracellular matrix promotes the growth and differentiation of murine hematopoietic cells in vitro. J Clin Invest. 1985;75(6):2085-90.

81. Nakano T, Kodama H, Honjo T. Generation of lymphohematopoietic cells from embryonic stem cells in culture. Science. 1994;265(5175):1098-101.

82. Cheadle E, Rothwell D, Bridgeman J, Sheard V, Hawkins R, Gilham D. Ligation of the CD2 co-stimulatory receptor enhances IL-2 production from first-generation chimeric antigen receptor T cells. Gene therapy. 2012;19(11):1114-20.

83. Wang X, Rivière I. Clinical manufacturing of CAR-T cells: foundation of a promising therapy. Molecular Therapy-Oncolytics. 2016;3:16015.

84. Luther DC, Lee YW, Nagaraj H, Scaletti F, Rotello VM. Delivery approaches for CRISPR/Cas9 therapeutics in vivo: advances and challenges. Expert Opin Drug Deliv. 2018;15(9):905-13.

85. Ou J, Si Y, Tang Y, Salzer GE, Lu Y, Kim S, et al. Novel biomanufacturing platform for large-scale and high-quality human T cells production. Journal of biological engineering. 2019;13(1):34. 
86. Palomero T, Ferrando A. Targeted cellular immunotherapy for T cell malignancies. Nat Med. 2017;23(12):1402-3.

87. Raetz EA, Teachey DT. T-cell acute lymphoblastic leukemia. Hematology Am Soc Hematol Educ Program. 2016;2016(1):580-8.

88. Iyer RK, Bowles PA, Kim H, Dulgar-Tulloch A. Industrializing Autologous Adoptive Immunotherapies: Manufacturing Advances and Challenges. Frontiers in Medicine. 2018;5(150).

89. Papathanasiou MM, Stamatis C, Lakelin M, Farid S, Titchener-Hooker N, Shah N. Autologous CAR-T-cell therapies supply chain: challenges and opportunities? Cancer Gene Therapy. 2020;27(10):799809.

90. Nagano S, Maeda T, Ichise H, Kashima S, Ohtaka M, Nakanishi M, et al. High Frequency Production of T Cell-Derived iPSC Clones Capable of Generating Potent Cytotoxic T Cells. Mol Ther Methods Clin Dev. 2020;16:126-35.

91. Loh YH, Hartung O, Li H, Guo C, Sahalie JM, Manos PD, et al. Reprogramming of T cells from human peripheral blood. Cell Stem Cell. 2010;7(1):15-9.

92. Seki T, Yuasa S, Oda M, Egashira T, Yae K, Kusumoto D, et al. Generation of induced pluripotent stem cells from human terminally differentiated circulating T cells. Cell Stem Cell. 2010;7(1):11-4.

93. Staerk J, Dawlaty MM, Gao Q, Maetzel D, Hanna J, Sommer CA, et al. Reprogramming of human peripheral blood cells to induced pluripotent stem cells. Cell Stem Cell. 2010;7(1):20-4.

94. Netsrithong R, Promnakhon N, Boonkaew B, Vatanashevanopakorn C, Pattanapanyasat K, Wattanapanitch M. Generation of two induced pluripotent stem cell lines (MUSIi011-A and MUSIi011-B) from peripheral blood T lymphocytes of a healthy individual. Stem Cell Res. 2019;39:101487.

95. Saito H, Okita K, Fusaki N, Sabel MS, Chang AE, Ito F. Reprogramming of Melanoma TumorInfiltrating Lymphocytes to Induced Pluripotent Stem Cells. Stem Cells Int. 2016;2016:8394960.

96. Kelly JM, Darcy PK, Markby JL, Godfrey DI, Takeda K, Yagita H, et al. Induction of tumor-specific T cell memory by NK cell-mediated tumor rejection. Nat Immunol. 2002;3(1):83-90.

97. Liem NT, Van Phong N, Kien NT, Anh BV, Huyen TL, Thao CT, et al. Phase I Clinical Trial Using Autologous Ex Vivo Expanded NK Cells and Cytotoxic T Lymphocytes for Cancer Treatment in Vietnam. Int J Mol Sci. 2019;20(13).

98. Johnson LA, Morgan RA, Dudley ME, Cassard L, Yang JC, Hughes MS, et al. Gene therapy with human and mouse T-cell receptors mediates cancer regression and targets normal tissues expressing cognate antigen. Blood. 2009;114(3):535-46.

99. Morgan RA, Dudley ME, Wunderlich JR, Hughes MS, Yang JC, Sherry RM, et al. Cancer regression in patients after transfer of genetically engineered lymphocytes. Science. 2006;314(5796):126-9.

100. Chapuis AG, Ragnarsson GB, Nguyen HN, Chaney CN, Pufnock JS, Schmitt TM, et al. Transferred WT1-reactive CD8+ T cells can mediate antileukemic activity and persist in post-transplant patients. Sci Transl Med. 2013;5(174):174ra27.

101. Rosenberg SA, Yang JC, Sherry RM, Kammula US, Hughes MS, Phan GQ, et al. Durable complete responses in heavily pretreated patients with metastatic melanoma using T-cell transfer immunotherapy. Clin Cancer Res. 2011;17(13):4550-7.

102. Depil S, Duchateau P, Grupp SA, Mufti G, Poirot L. 'Off-the-shelf' allogeneic CAR-T cells: development and challenges. Nat Rev Drug Discov. 2020;19(3):185-99.

103. Deol A, Lum LG. Role of donor lymphocyte infusions in relapsed hematological malignancies after stem cell transplantation revisited. Cancer Treat Rev. 2010;36(7):528-38. 
104. Matutes E. Adult T-cell leukaemia/lymphoma. J Clin Pathol. 2007;60(12):1373-7.

105. Perdomo-Celis F, Taborda NA, Rugeles MT. CD8+ T-Cell Response to HIV Infection in the Era of Antiretroviral Therapy. Frontiers in Immunology. 2019;10(1896).

106. Yanada M, Konuma T, Yamasaki S, Kondo T, Fukuda T, Shingai N, et al. Relapse of acute myeloid leukemia after allogeneic hematopoietic cell transplantation: clinical features and outcomes. Bone Marrow Transplantation. 2020 .

107. Brentjens RJ, Rivière I, Park JH, Davila ML, Wang X, Stefanski J, et al. Safety and persistence of adoptively transferred autologous CD19-targeted $\mathrm{T}$ cells in patients with relapsed or chemotherapy refractory B-cell leukemias. Blood. 2011;118(18):4817-28.

108. Ritchie DS, Neeson PJ, Khot A, Peinert S, Tai T, Tainton K, et al. Persistence and efficacy of second generation CAR-T cell against the LeY antigen in acute myeloid leukemia. Mol Ther. 2013;21(11):2122-9.

109. Schuster SJ, Svoboda J, Chong EA, Nasta SD, Mato AR, Anak Ö, et al. Chimeric Antigen Receptor T Cells in Refractory B-Cell Lymphomas. N Engl J Med. 2017;377(26):2545-54.

110. Rouce RH, Fousek K, Ahmed N, Gottschalk S, Savoldo B, Dotti G, et al. Safety of multiple doses of CAR-T cells. American Society of Hematology Washington, DC; 2015.

111. Azzaoui I, Uhel F, Rossille D, Pangault C, Dulong J, Le Priol J, et al. T-cell defect in diffuse large B-cell lymphomas involves expansion of myeloid-derived suppressor cells. Blood. 2016;128(8):1081-92.

112. Das RK, Vernau L, Grupp SA, Barrett DM. Naïve T-cell Deficits at Diagnosis and after Chemotherapy Impair Cell Therapy Potential in Pediatric Cancers. Cancer Discov. 2019;9(4):492-9.

113. Ruella M, Xu J, Barrett DM, Fraietta JA, Reich TJ, Ambrose DE, et al. Induction of resistance to chimeric antigen receptor $\mathrm{T}$ cell therapy by transduction of a single leukemic B cell. Nat Med. 2018;24(10):1499-503.

114. Garfall AL, Dancy EK, Cohen AD, Hwang WT, Fraietta JA, Davis MM, et al. T-cell phenotypes associated with effective CAR-T-cell therapy in postinduction vs relapsed multiple myeloma. Blood Adv. 2019;3(19):2812-5.

115. Gattinoni L, Lugli E, Ji Y, Pos Z, Paulos CM, Quigley MF, et al. A human memory T cell subset with stem cell-like properties. Nat Med. 2011;17(10):1290-7.

116. Hu Y, Wang J, Wei G, Yu J, Luo Y, Shi J, et al. A retrospective comparison of allogenic and autologous chimeric antigen receptor $\mathrm{T}$ cell therapy targeting CD19 in patients with relapsed/refractory acute lymphoblastic leukemia. Bone Marrow Transplant. 2019;54(8):1208-17.

117. Kochenderfer JN, Dudley ME, Carpenter RO, Kassim SH, Rose JJ, Telford WG, et al. Donorderived CD19-targeted $\mathrm{T}$ cells cause regression of malignancy persisting after allogeneic hematopoietic stem cell transplantation. Blood. 2013;122(25):4129-39.

118. Taylor CJ, Peacock S, Chaudhry AN, Bradley JA, Bolton EM. Generating an iPSC bank for HLA-matched tissue transplantation based on known donor and recipient HLA types. Cell Stem Cell. $2012 ; 11(2): 147-52$.

119. Wieczorek M, Abualrous ET, Sticht J, Álvaro-Benito M, Stolzenberg S, Noé F, et al. Major Histocompatibility Complex (MHC) Class I and MHC Class II Proteins: Conformational Plasticity in Antigen Presentation. Front Immunol. 2017;8:292.

120. Xu H, Wang B, Ono M, Kagita A, Fujii K, Sasakawa N, et al. Targeted Disruption of HLA Genes via CRISPR-Cas9 Generates iPSCs with Enhanced Immune Compatibility. Cell Stem Cell. 2019;24(4):566-78.e7.

121. Cunningham JJ, Ulbright TM, Pera MF, Looijenga LH. Lessons from human teratomas to guide development of safe stem cell therapies. Nat Biotechnol. 2012;30(9):849-57. 
122. Nianias A, Themeli M. Induced Pluripotent Stem Cell (iPSC)-Derived Lymphocytes for Adoptive Cell Immunotherapy: Recent Advances and Challenges. Curr Hematol Malig Rep. 2019;14(4):261-8.

123. Duncan EJ, Gluckman PD, Dearden PK. Epigenetics, plasticity, and evolution: How do we link epigenetic change to phenotype? J Exp Zool B Mol Dev Evol. 2014;322(4):208-20.

124. Keller A, Dziedzicka D, Zambelli F, Markouli C, Sermon K, Spits C, et al. Genetic and epigenetic factors which modulate differentiation propensity in human pluripotent stem cells. Hum Reprod Update. 2018;24(2):162-75.

125. Yadav RK, Ali A, Kumar S, Sharma A, Baghchi B, Singh P, et al. CAR-T cell therapy: newer approaches to counter resistance and cost. Heliyon. 2020;6(4):e03779.

Table 1. iPSC-derived $\mathrm{T}$ cell generation from peripheral blood mononuclear cells

\begin{tabular}{llll}
\hline Somatic Cell Source & Reprogramming Factors & Delivery Method & Mor \\
PBMC & Oct3/4, Klf4, Sox2, and c-Myc & Polycistronic lentiviral vector & A n \\
PBMC & Oct3/4, Klf4, Sox2, and c-Myc & Temperature-sensitive mutated Sendai viral vector & Pos \\
PBMC & Oct3 $/ 4$, Klf4, Sox2, and c-Myc & Two lentiviruses, each encoding two reprogramming factors & iPS \\
Melanoma TILs & Oct3 $/ 4$, Klf4, Sox2, and c-Myc & Sendai viral vector & Pos \\
CD8 CTL & Oct3/4, Klf4, Sox2, and c-Myc & Sendai viral vector & A n \\
\hline
\end{tabular}

\section{Caption for figures}

Figure 1. Schematic representation of CAR, TCR, and iPSC constructions. (A) CAR is a synthetic receptor expressed on the surface of $\mathrm{T}$ lymphocytes. This receptor has both extracellular and intracellular domains. The extracellular constitutes an antigen-recognizing domain and a spacer, while the intracellular component includes the transmembrane domain, co-stimulatory domain, and intracellular signaling domain. (B) TCR is comprised of mainly $\alpha \beta$ heterodimers which noncovalently associated with CD3 complex, including CD3ع $\gamma$,

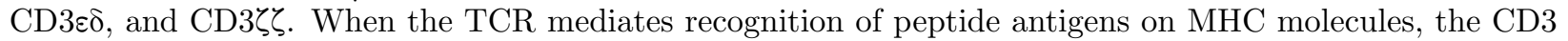
complex transduces activation signals to the T lymphocytes. (C) Reprogramming of PBMCs with four transcription factors (Oct4, Sox2, c-Myc, and Klf4) results in iPSC-derived T cells. However, the iPSCderived $\mathrm{T}$ cells might be a $\mathrm{CD} 8 \alpha \beta$ heterodimer or $\mathrm{CD} 8 \alpha \alpha$ homodimer. A normal functional $\mathrm{CD} 8^{+} \mathrm{T}$ cells is a D8 $\alpha \beta$ heterodimer; therefore, the generated T-iPSCs should be determined for CD8 $\alpha \beta$ heterodimer expression.

Figure 2. The scheme of iPSC establishment. PBMCs are collected using the leukapheresis procedure and they undergo depletion and enrichment process for a certain cell subset. A specific T cell population is ready to reprogram through the introduction of defined transcription factors either Oct4, Sox2, Nanog, and Lin28 or Oct4, Sox2, Klf4, and c-Myc. The delivery methods predominantly lie in two methods, including integrative methods (using lentiviral and retroviral vectors) and non-integrative methods (using Sendai virus vectors, plasmid transfection, synthetic messenger RNA, and transposon vectors). The reprogrammed $\mathrm{T}$ cells turn into hematopoietic stem and progenitor cells (HSPCs) that have the potential to generate common lymphoid progenitors for $\mathrm{T}$ lymphocyte development. The produced $\mathrm{T}$ cells are known as iPSC-derived $\mathrm{T}$ cells that are characterized by a set of markers that are exclusively related to their pluripotency attitudes. Afterward, the iPSC-derived $\mathrm{T}$ cells undergo expansion process by different procedures for therapeutic purposes.

Figure 3. Formation of white blood cells derived from hematopoietic stem cells (HSCs). Multipotent HSCs give rise to oligopotent progenitors, including the common lymphoid progenitor (CLP) and common myeloid 
progenitor (MLP). The former gives rise to mature T lymphocytes, B lymphocytes, and natural killer cells. While, the latter gives rise to Monocytes and granulocytes, such as Neutrophils, Eosinophils, and Basophils.

Figure 4. Manufacturing of off-the-shelf CAR-T cells. The manufacturing process of off-the-shelf CAR-T cells start with collecting T cells from third-party healthy volunteers or iPSC-derived T cells. The collected $\mathrm{T}$ cells get activated by one of these methods, such as artificial antigen presenting cells (K562 cells), Interleukins (IL-2, IL-7, and IL-15), and anti-CD3/CD28 antibodies coated magnetic beads. The activated T cells are ready for CAR gene delivery and CRISPR/Cas9 system delivery. Technologies such as viral vectors (lentivirus and retrovirus) and non-viral vectors (mRNA, electroporation of naked DNA and plasmid-based transposon/transposase) can be used for transgenesis. CRISPR/cas9 genome editing technology can eliminate $\alpha \beta$ TCR and HLA protein to make the T cells a universal product that have the potential to benefit multiple patients without causing severe side effects and no need for HLA match. The off-the-shelf CAR-T cells are then expanded using certain cytokines and anti-CD3/anti-CD28 beads. The non-transduced T cells, CAR negative T cells and $\alpha \beta$ TCR-positive, undergo positive and negative selection process using magnetic anti- $\alpha \beta$ TCR antibodies and anti-CAR antibodies, respectively. The off-the-shelf products are then either cryopreserved or send to hospitals for therapeutic purposes.

A

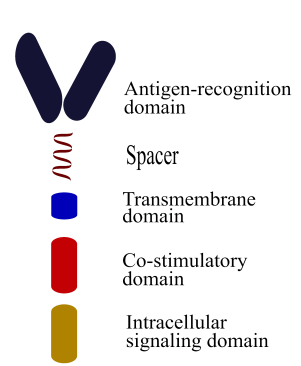

CAR structure

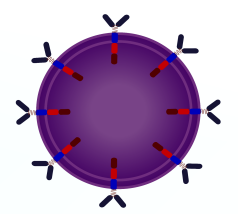

CAR-T cell

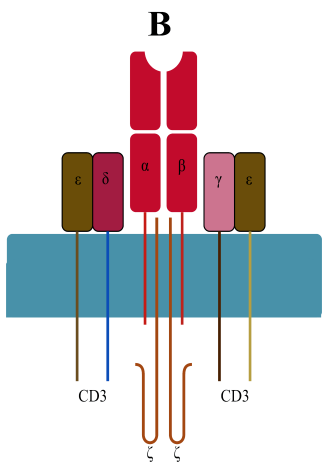

TCR structure

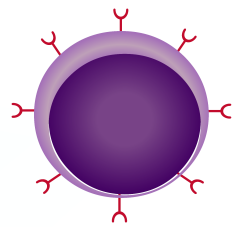

$\mathrm{T}$ cell

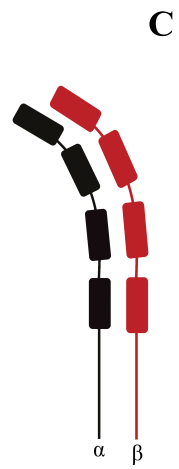

Heterodimer CD8 receptor

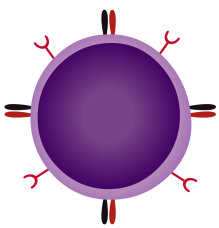

CD8 $\alpha \beta$ iPSCderived T cell

C

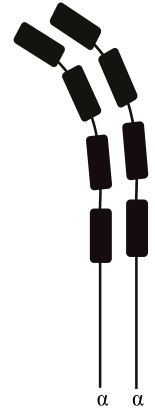

Homodimer CD8 receptor

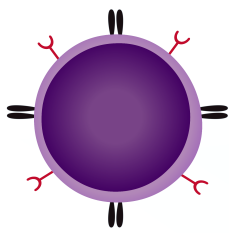

CD $8 \alpha \alpha$ iPSC derived $\mathrm{T}$ cell 

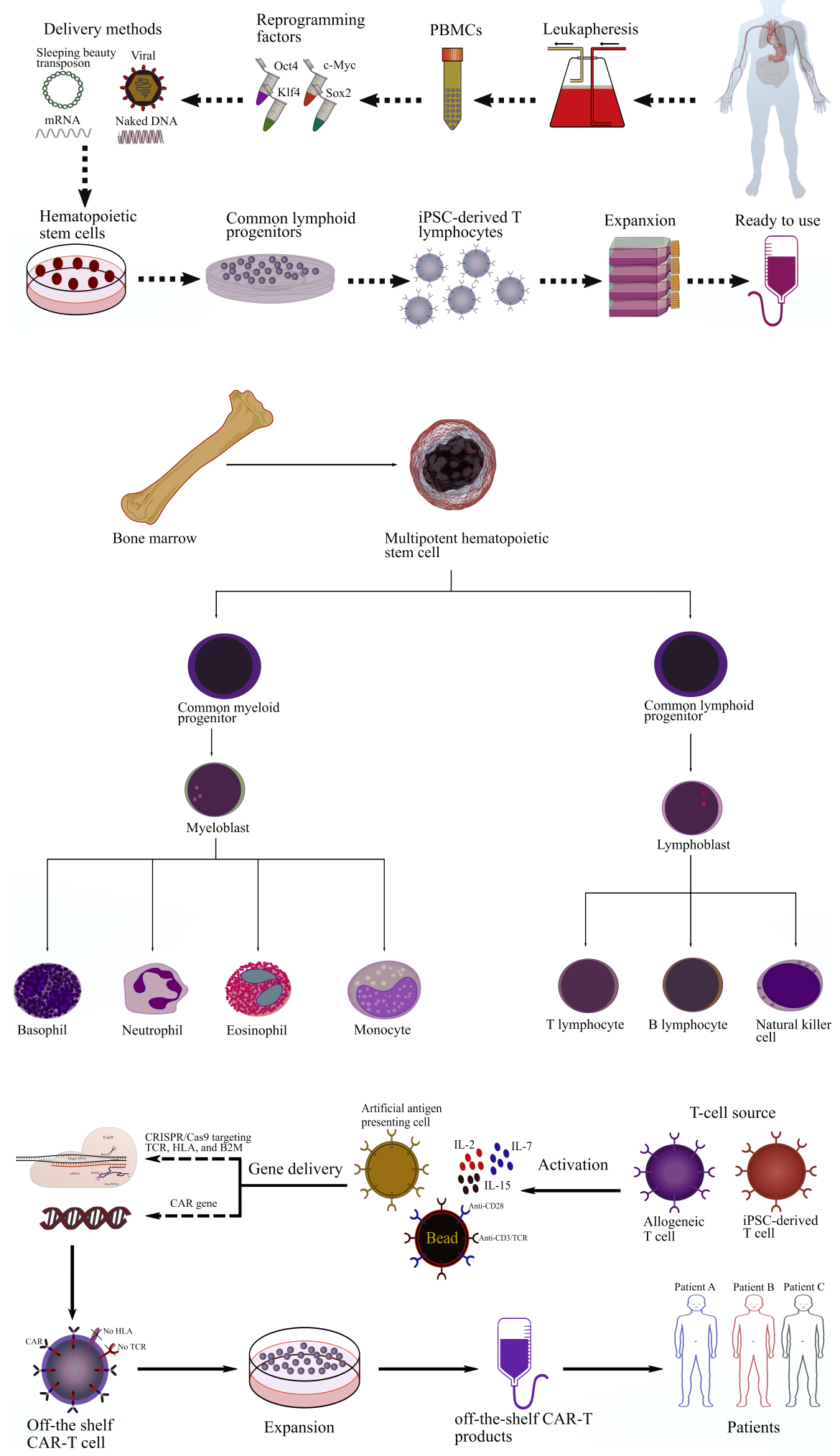